\title{
CONSIDERAÇÕES PRELIMINARES A TODO TRATAMENTO POSSÍVEL DO AUTISMO
}

\author{
Preliminary considerations on any possible treatment to autism
}

\begin{abstract}
Alfredo Jerusalinsky
Psicólogo, Mestre em Psicologia Clínica, Doutor em Educação e Desenvolvimento Humano, psicanalista membro da Associação Psicanalítica de Porto Alegre e da Association Lacaniènne Internationale, Porto Alegre, RS - Brasil, e-mail: jerusalf@uol.com.br
\end{abstract}

\section{Resumo}

O autor traça um paralelo entre o tratamento comportamental e o tratamento psicanalítico do autismo, enfatizando as consequências respectivas tanto da concepção da "incurabilidade" do autismo, quanto da "aposta no surgimento de um sujeito". Analisa a oposição entre os automatismos neurobiológicos inatos e a produção das estruturas psíquicas mínimas pela intervenção do Outro Primordial e, na sua substituição, pela intervenção do psicanalista, e evidencia a importância etiológica das identificações primárias. Fornece diretivas para um tratamento psicanalítico da criança autista, a partir de sua experiência como analista que segue a teoria lacaniana, em contraponto à abordagem de outros psicanalistas da escola inglesa.

Palavras-chave: Autismo. Psicanálise. Tratamento. Sujeito.

\begin{abstract}
The author traces a parallel between the behaviorist treatment and the psychoanalytic treatment to emphasize the respective consequences of the "incurability" conception of autism, same so of the "bet in the appearance of a subject". It analyses the opposition between the constitutional neurobiological automatisms and the production of minimal physiques structures by the Primordial Other intervention, or, in case of substitution, by the psychoanalyst. The author gives evidences about the etiological importance of the primary identifications and also gives some directions to a psychoanalytic treatment of the autistic child, parting from his experience as an analyst who follows the Lacan's theory, as a counterpoint to the other psychoanalytic approaches of the English school.
\end{abstract}

Keywords: Autism. Psychoanalysis. Treatment. Physique Subject. 
No fim da década de 1980 fui convocado, por uma associação de pais de autistas, para participar de uma mesa de contraponto em Buenos Aires com um terapeuta comportamentalista espanhol, Jorge Rivier, reconhecido especialista em autismo. Homem muito inteligente e de grande honestidade científica, Jorge Rivier permitiu que o debate entre sua perspectiva e a vertente psicanalítica por mim defendida apontasse os problemas clínicos mais relevantes na abordagem do autismo. Revisando esse material vinte anos mais tarde, viemos a perceber o quanto ele conserva sua atualidade. Por tal motivo reproduzimos parcialmente aqui as ideias que se colocaram em jogo naquele debate.

O psicoterapeuta espanhol colocava a questão genética em primeiro lugar. "O senhor não pode discutir que há transtornos genéticos, porque isto tem sido comprovado. E não pode discutir que esses transtornos genéticos dão transtornos de conduta que são universais". Minha resposta:

Não discuto que há transtornos genéticos coincidentes com autismo num certo número de casos, mas não em todos - é claro que o senhor vai me dizer que aqueles que não apresentam alterações genéticas não se tratam de verdadeiros autistas - e devo lhe apontar que a condição genética não é a única capaz de produzir transtornos de conduta universais. Por isso o que proponho é que o genético - no autismo - não deve atuar como limite para nossa perspectiva clínica (Jerusalinsky, 1989, p. 56).

Jorge Rivier ainda insistiu: Sua posição merece simpatia e é muito interessante isso que o senhor coloca de fazermos uma aposta de que ali possa haver um sujeito. Mas não é o que eu vejo. E me parece injusto, e nisso não concordo, dar aos pais destas crianças esperanças totalmente fora das possibilidades. Não é justo porque quando essas crianças adquirem certos hábitos de sociabilidade, evidentemente, os pais logram estabelecer uma relação melhor com elas. Enfim, se faz o que se pode com esses quadros. seguintes termos:

A discrepância foi por mim colocada nos

A aposta num sujeito é fundamental no tratamento do autismo. Não porque efetivamente já houvesse um sujeito aí (onde os automatismos neurobiológicos prevalecem), mas, porque segundo o demonstra a evolução favorável de numerosos casos - existe a possibilidade de constituir um sujeito (Jerusalinsky, 2008, p. 57).

Diante da objeção "a injustiça de convocar os pais para um trabalhoso tratamento psicanalítico", eis aqui nossa contestação:

1. declarar desde o início a incurabilidade de todo e qualquer caso de autismo sob o argumento de sua possível causa genética (numa vasta proporção deles tal falha é suposta, sem comprovação) tem como consequência submeter aqueles que poderiam aceder a uma condição de sujeito a um tratamento (de construção de condicionamentos de automatismos mais adaptativos) que, por cultivar automatismos, cancela qualquer chance desse sujeito de desejo vir a se constituir, confirmando, desse modo tautológico, a incurabilidade inicialmente declarada;

2. para poupar os pais de uma suposta "injustiça", eles são condenados àinjustiça - e essa não suposta, mas verdadeira - de cancelar qualquer esperança onde legitimamente poderia havê-la;

3. "fazer o que se pode com esses quadros" somente é definível, nos seus limites, depois de tentá-lo, embora possa haver em muitos casos uma base genética irremovível. De fato, no que se refere à qualidade e à particular estrutura do sujeito que em cada caso se instala a história, as diferentes culturas e a psicopatologia demonstram que constituições genéticas equivalentes dão resultados enormemente diferentes, de acordo com as condições psíquicas a que são submetidas;

4. os pais que se sentem "injustamente" tratados pela psicanálise são precisamente aqueles cujos filhos não se curaram. O comportamentalismo associado ao fatalismo neurogenético evade esse problema, porque declara os autistas incuráveis já de início: as melhorias que se obtêm por seu método conservam a criança no âmbito da incurabilidade. 
Assim as diferentes intervenções terapêuticas causam a diferenciação de três grupos de pais:

a) os que se arriscaram na tentativa de fazer de seus filhos sujeitos desejantes e obtiveram certo nível de sucesso com seus psicanalistas (esses geralmente esquecem a gravidade que afetou seu filho - o que é de beneficio no fim da cura);

b) os que se sentem injustamente tratados porque tentaram esse caminho e seus filhos não se curaram (o que de fato acontece sempre em alguma proporção, em qualquer tipo de tentativa terapêutica);

c) os que se resignam de entrada à incurabilidade suposta de seus filhos e constroem uma falsa ou parcial satisfação com os automatismos adaptativos atingidos.

Conseguir uma cura psicanalítica depende da precocidade do início do tratamento (quanto mais cedo, maiores são as probabilidade de cura e, de um modo geral, maiores são as conquistas), enquanto a implantação de automatismos adaptativos condicionados é viável a qualquer altura do desenvolvimento humano (ainda que não o seja na mesma medida de plasticidade). Um fracasso psicanalítico não impede de procurar depois uma tentativa comportamentalista, mas o contrário não é verdadeiro. Os pais que costumam se incluir nas associações de pais de autistas, geralmente são pais de filhos que não se curaram; seja porque tentaram a cura psicanalítica e ela não prosperou, seja porque se resignaram muito cedo, concordando com alguma declaração profissional de incurabilidade. De fato, os pais de crianças tratadas cedo, e que se curaram, têm muitos mais motivos para ficarem fora dessas associações do que para estar dentro delas: não é bom nem para eles nem para seus filhos que se faça presente aquele passado autista.

É lógico, então, que nessas associações não impere a simpatia pela psicanálise. Tal equação costuma favorecer uma atitude antipsicanalítica que implica um risco iatrogênico: a escolha, para crianças muito pequenas que apresentam riscos de autismo, de um método terapêutico selecionado na base da resignação à sua incurabilidade.

Há uma longa e vasta experiência de intervenções clínicas psicanalíticas em diversas patologias e condições genéticas, com a obtenção de sucessos surpreendentes no plano da constituição de um sujeito de desejo sob circunstancias e constituições notadamente adversas.

A experiência clínica demonstra que o sujeito nasce à mercê de um ato de ruptura da identidade, o que permite, precisamente, a identificação. Para os humanos nada faz diferença no real - por isso o real funciona para nós como a essência da aleatoriedade -, já que é o significante que introduz os cortes nesse infinito indiferenciado onde o discurso, ao quebrar o idêntico a si mesmo, captura esse registro indeterminado num prisma de determinações de destino. Estamos, então, afirmando que o estado inicial do ser humano não é de normalidade, mas de funcionamento de automatismos neurobiológicos que por si mesmos não garantem nada. Que eles "funcionem bem" permitirá que a "normalidade" seja mais facilmente conquistada. Que eles "funcionem mal" criará dificuldades para a obra do significante. Que eles prevaleçam criará uma barreira de resistência ativa contra a linguagem.

Lacan ([1960-1961] 1992) enlaça o nascimento do sujeito ao traço unário e não ao investimento de qualquer objeto. Coloca para nós, então, no que se refere à cura do autismo, a tarefa de desvendar o detalhe da constituição das estruturas mínimas capazes de introduzir esse traço unário ainda nas condições mais adversas. Não se trata de retornar a uma normalidade inicial (que os automatismos precoces no autista desmentem). Trata-se da intromissão arbitrária do Outro que, em posição Primordial, orientado pelo significante, seja capaz de criar a cena onde a letra faça marca sobre os automatismos neurobiológicos. Traço que, para se produzir, precisa da ruptura de uma continuidade.

Assim, o primeiro passo do tratamento requer que o analista se identifique literalmente com os automatismos dos autistas, em continuidade com ele, única repetição até aí em que o autista 'se reconhece'. Mas, não para recompor uma identidade perdida, senão, muito pelo contrário, para, do interior mesmo dela, adquirir a possibilidade de quebrá-la: uma tênue, mas firme descontinuidade traçada na pequena distância que permita ao autista percebê-la na dimensão de esboço de um estranhamento. Um estranhamento que, pela primeira vez não passa pelo aleatório dos objetos que se precipitam como um meteoro: mas que passa pela arbitrariedade do outro que, a partir daí, lê essa marca como letra. 
Não é por acaso que, com curiosa frequência, uma das primeiras palavras que a criança autista pronuncia é "cai" ou "caiu". Tudo indica que, uma vez situado esse primeiro traço, ela pode enunciar desde sua nova posição, cingida à letra, o aleatório do real como algo que, desde esse momento, lhe é alheio: o objeto caiu. Talvez seja esse o primeiro momento em que seja legítimo falarmos de objeto "a" no autismo.

Perceba-se aqui que estamos marcando um caminho diferente daquele que supõe uma normalidade autística inicial, segundo Margaret Mahler (1983), de uma normalidade simbiótica inicial (a célula narcísica mãe-filho), segundo Donald W. Winnicott (1983), tanto quanto daquele que supõe uma condição neurológica originária normal como suficiente para uma adequada evolução. Esses supostos, naturalmente, levam a propor um tratamento baseado no retorno a essas "normalidades" hipotéticas. É claro que numa perspectiva behaviorista qualquer "normalidade", seja do passado, do presente ou do futuro, transforma-se imediatamente num projeto de adestramento.

Se para Bruno Bettelheim (1987) o autista constrói ao seu redor o muro de uma fortaleza para manter fora dela os horrores que o habitam (o que, no fundo, coloca a 'fortaleza vazia' de Bettelheim como demasiadamente cheia), para Hector Yankelevich (2004) o tratamento requer quebrar o ovo de autoabastecimento no qual o autista se fornece seu próprio gozo numa espécie de evolução que aperfeiçoa os mecanismos desse gozo absoluto gerado e provido em circuitos totalmente próprios. Para ele também essa quebra precisa se operar no campo da letra.

Para nós, a continuidade que ali se rompe não é a de uma criança com a sua mãe, nem a da totalidade do ovo mítico, mas a de uma identidade absoluta (que no autista aparece sob a forma de automatismos) que por estar constituída como uma totalidade se opõe a qualquer diferença. É por isso que as repetições autistas são idênticas e resistem à repetição da diferença reclamada pelo traço unário. Essa parece ser a razão para os autistas rechaçarem especialmente o Outro (sob todos seus disfarces imaginários) na medida em que esse Outro, pela lógica que o governa, insiste, seja em ler sua repetição como letra, seja em forçá-lo a responder em submissão à imposição de uma ordem discursiva - imperativos de cuja lógica o autista se sente alheio e, diante da imposição, excluído.
O pouco ou muito que de 'sujeito' possa navegar nos automatismos autistas, certamente reside nesse avesso do real que nos autistas prevalece sob a forma de uma identidade absoluta. E que, para seu infortúnio, os exclui inicialmente do campo significante. Esse é o ponto nodal, a nosso entender, o ponto de partida de qualquer tentativa psicanalítica da cura de um autista. Para isso é necessário se deixar arrastar por uma transferência que ataca qualquer tentativa de alteridade e se opõe "automaticamente" a qualquer proposição de descontinuidade. Nenhuma outra experiência clínica nos arranca tão radicalmente do campo do significante, embora se trate de uma hipérbole para retornar, na esperança de que nosso pequeno autista fique enredado na teia das letras com que o levamos a tropeçar.

\section{Esquema dos passos iniciais no tratamento do autismo}

A experiência clínica com bebês ensina de modo exemplar esse momento princeps em que o objeto que fez a marca da satisfação sobre o corpo do pequeno desaparece e fica substituído pela sua representação fonemática (Jerusalinsky, 2002). Momento crucial em que o representante não representacional (no litoral da letra) adquire o poder de provocar a mesma inquietação que o objeto real até então produzia. Mas para isso acontecer requerem-se duas condições: a primeira, que o Outro primordial deixe cair o objeto renunciando ao poder que ele lhe outorga e entregando ao bebê o poder de representá-lo e evocá-lo per se; a segunda, que no bebê não prevaleça o automatismo de ligação física ao objeto - fonte de gozo primordial (na ordem de um narcisismo primário) - para moldar a voz na ordem do Outro que faz dela, a partir desse momento, já não mais pequeno objeto de gozo, mas instrumento da linguagem.

Precisamente na criança autista encontramo-nos com sérias dificuldades para deixar cair o objeto: a prolongação exorbitante da alimentação líquida e a resistência ao alimento sólido, o fascínio pela luminosidade intensa, o mergulho no gozo da propriocepção autoestimulada pelo rocking, a agitação de pequenas coisas na frente dos olhos são alguns exemplos; e também com a prevalência dos automatismos de ligação física aos pequenos objetos. Tais condições exigem que nosso trabalho 
terapêutico percorra a decomposição, passo a passo, das operações que sejam capazes de provocar no autista essa separação entre o traço e a coisa, mas de um modo tal que não o convoquemos a substituir um automatismo por outro, senão a produzir a torção que venha a fazer do traço letra.

Eis aqui uma pontuação dessa desmontagem dos passos mais elementares na tentativa de constituir estruturas mínimas de suporte para um sujeito:

1. identificação do analista aos automatismos da criança autista;

2. determinação da janela pulsional daquela forma da pulsão que eventualmente tenha ficado preservada da experiência de exclusão com o Outro, ou, contra sensu, que constitua a forma predileta de gozo para esse autista;

3. montagem de uma descontinuidade mínima nos automatismos compartilhados.

4. alongamento do intervalo(ritmo/letra);

5. alternância do "sujeito" de partida da discrepância do ritmo, ora quebrando o ritmo da criança ora obedecendo ao ritmo dela em discrepância;

6. variação da repetição (introdução de um movimento/fonema surpresa);

7. alternância de presença/ausência (Fort-Da);

8. substituição do movimento por cenas. Repetição de cenas com sequência;

9. inversãodademanda:objetotransicional; 10. jogos de borda: transbordamentos, objeto que cai, circunscrições, correspondências, traços.

Trata-se de articulações mínimas que constituem tentativas de engatar os automatismos à instância da letra. Fácil é observar - e para qualquer psicanalista isso pode dar pé a inúmeras objeções quanto nos distanciamos, nessas proposições, do campo da linguagem. Mas somente percorrendo com o autista as estepes ermas dos objetos sem nome, como se fossem pedras espalhadas ao acaso num planeta perdido, e fazendo do uivo do vazio uma tímida e inesperada música, é que teremos chance-e, por consequência, ele terá chance - de engatar sua escuta numa letra, seu olho num traço significante.
Portador de um contrabando da linguagem para o território excluído dela, o psicanalista convoca o autista à cumplicidade de se enlaçarem numa língua que mais ninguém, e somente eles, inicialmente compreendem.

\section{REFERÊNCIAS}

Bettelheim, B. (1987). A fortaleza vazia. São Paulo: Martins Fontes.

Jerusalinsky, A. (1989). Psicanálise do autismo. Porto Alegre: Artes Médicas.

Jerusalinsky, A. (2008). Saber falar. Petrópolis: Vozes.

Jerusalinsky, J. (2002). Enquanto o futuro não vem. Salvador: Agalma.

Lacan, J. ([1960-1961] 1992). O seminário, livro 8: A transferência. Rio de Janeiro: Jorge Zahar.

Mahler, M. (1983). As psicoses infantis e outros estudos. Porto Alegre: Artes Médicas.

Winnicott, D. W. (1983). O ambiente e os processos de maturação. Porto Alegre: Artmed.

Yankelevich, H. (2004). Do pai à letra. Rio de Janeiro: Companhia de Freud.
Recebido: 23/03/2009

Received: 03/23/2009

Aprovado: 04/05/2009

Approved: 05/04/2009 